\title{
Worker-firm relational contracts in the time of shutdowns: experimental evidence
}

\author{
Sera Linardi ${ }^{1}$ (D) Colin Camerer ${ }^{2}$
}

Received: 4 August 2020 / Revised: 6 December 2020 / Accepted: 22 December 2020 /

Published online: 15 February 2021

(c) Economic Science Association 2021

\begin{abstract}
Exogeneous disruptions in labor demand have become more frequent in recent times. The COVID-19 pandemic has resulted in millions of workers being repeatedly laid off and rehired according to local public health conditions. This may be bad news for market efficiency. Typical employment relations-which resemble non-enforceable (implicit) contracts-rely on reciprocity (Brown et al. in Econometrica 72:747-780, 2004), and hence could be harmed when workers' efforts no longer guarantee reemployment in the next period. In this paper we extend the BFF paradigm to include a per-period probability $(0 \%, 10 \%, 50 \%)$ of publicly observable "shutdown", where a specific firm cannot contract with any workers for several periods. A Perfect Bayesian Equilibrium exists in which these shutdowns destabilize relationships, but do not harm efficiency. Our experiment shows that, remarkably, market efficiency can be maintained even with very frequent stochastic shutdowns. However, the dynamic of relational contracts changes from one where a worker finds stable employment to one where she juggles multiple employers, laying the burden of maintaining productivity upon workers and worsening worker-side inequality.
\end{abstract}

Keywords Relational contracts · Gift exchange · Labor markets · Unemployment · Shocks $\cdot$ Layoffs $\cdot$ Recession $\cdot$ Repeated game

JEL Classification J23 · J31 · J64 · C92

\footnotetext{
The authors would like to thank the following individuals for their excellent research assistance: Erin Carbone, Xiaohong Wang, Jinyong Jeong, Taisuke Imai, Devdeepta Bose. We thank the referees, editors, and participants at seminars for their very useful feedback. We acknowledge the financial support from Behavioral and Neuroeconomics Discovery Fund (via MacArthur Foundation) and grant administration assistance of Tiffany Kim and Alisha Cunniff.

Sera Linardi

linardi@pitt.edu

Colin Camerer

camerer@caltech.edu

1 University of Pittsburgh, Pittsburgh, USA

2 California Institute of Technology, Pasadena, USA
} 


\section{Introduction}

Disruptions in labor demand often occur in everyday labor markets. This is a more common experience for workers in certain sectors with high failure rates or seasonality of consumer demand (e.g. hospitality, entertainment, service, and high-tech start-ups). However, the recent coronavirus pandemic has resulted in temporary unemployment for about 25 million workers-affecting workers across the economy, including those employed in typically stable sectors. ${ }^{1}$ These disruptions are likely to continue into the future as many conditions for reopening require businesses to shut down when local public health conditions (e.g. infection and testing rates) do not remain below government requirements. ${ }^{2}$ More generally, firm-worker relationships can be interrupted by many exogenous reasons such as business cycle effects, liquidity shocks, or changes in upper management's priorities. ${ }^{3}$

Employment relations are tricky to navigate even without exogenous disruptions. Typical employment contracts specify the duration and terms of employment only loosely, leaving many details implicit (Williamson et al. 1975; Chevalier and Ellison 1997). ${ }^{4}$ In theory, since third parties cannot enforce implicit contracts, such contracts may be inefficient due to moral hazard. That is, after contracts are agreed upon, each party could take actions that undermine efficiency but which cannot be fully anticipated and contracted around. However, experimental evidence, such as from Brown et al. (2004) (BFF), has shown that high efficiency can be achieved under incomplete contracts through relational contracts-informal long-term relationships with no explicit guarantee of relationship continuation. These contracts are driven by reciprocity: firms offer high wages to specific workers, workers reward these firms with high effort, and the firms return the favor with immediate contract renewals. Mirroring naturally-occurring labor markets, this high-tier market often coexists with a low-tier market of "McJobs" in which firms make public (indiscriminate) low wage offers and workers who accept those jobs deliver low effort. ${ }^{5}$

Intuitively, stochastic disruptions can undermine relational contracts in many ways. Workers who are uncertain about the stability of their jobs may not find it worthwhile to invest effort to maintain goodwill, and shirk. Firms may lower wages in anticipation of such defensive shirking, resulting in lower market efficiency. ${ }^{6}$ But

\footnotetext{
1 See https://tinyurl.com/ilocoronavirus for global estimates. Cajner et al. (2020) find a 22\% contraction in U.S. private-sector employment between mid-February and mid-April.

2 For example: https://www.fox10phoenix.com/news/phoenix-area-restaurants-closing-again-due-topositive-covid-19-tests 1 .

3 In developing countries, weak legal enforcement and limited capital markets subject firms to exaggerated shocks, which in turn affect their contractors (Banerjee and Duflo 2000).

4 Most US firms use "employment at will" clauses, which state that either the firm or the worker can terminate an employment contract of indefinite duration at any time, for any reason. This clause renders the terms under which termination occurs vague and hence implicit in nature.

5 For the coexistence of well-paid permanent workers with poorly paid temporary workers in naturally occurring labor markets see Amuedo-Dorantes (2000) on Spain; Herrera and Shady (2005) on Peru; and Lindbeck and Snower (2001) on "insider-outsider" theory.

6 In relational contracts experiments, there are always high and low equilibria. Experiments in other domains with multiple equilibria have shown that exogenous random re-matching of agents can undermine efficiency (Camerer 2003, Chapter 7; Van Huyck et al. 1990, 1991; Anderson et al. 2001; Andreoni
} 
these shocks can conceivably improve market efficiency. Azariadis (1975) and Rute Cardoso and Portela (2009) argue that firms will provide workers with de facto unemployment insurance in the event of stochastic shocks (such as more generous wages), thus inducing positive reciprocity from the workers. Lazear et al. (2016) traced increased productivity during the recent 2008 recessions to incumbent workers working harder as their local unemployment rate rises, an effect they termed "making do with less." Putting this in the context of relational contracts, stochastic shocks may increase workers' anxiety over relationship continuation, driving workers to put in extra effort to keep their jobs or to improve their chances of being rehired in case of layoffs. Stochastic shutdowns may also improve market efficiency by accelerating productivity-enhancing reallocation (the "cleansing" effect of recession (Davis and Haltiwanger 1992)). However, Barlevy (2002) argues that as much as recession speeds the destruction of less efficient matches, it also slows the formation of the most efficient matches.

Laboratory experiments provide a useful first step to investigate the impact of temporal labor demand shocks on relational contracts. Unlike in naturally-occurring labor markets, complicating factors (such as uncertainty about the length or probability of shutdown, informal promises to rehire workers, or benefits offered to laidoff workers) can be controlled in the lab. Additionally, shocks that are truly independent and evidently exogenous can be easily created in the lab, allowing us to study relationship shocks in the simplest setting. ${ }^{7}$ Our experiment extends the BFF gift-exchange paradigm as follows: in every period, there is a probability that a firm experiences a publicly observable stochastic shock, which forces a three-period shutdown. The firm can observe the market during the shutdown, but is unable to contract with any workers. We employ three treatments: No Shutdowns, Infrequent (shutdowns), and Frequent (shutdowns). ${ }^{8}$

We develop a theory that follows previous literature in assuming the existence of some known proportions of fair (non-shirking) workers and selfish workers (cf. BFF and Bernard et al. 2018). We show that there is a perfect Bayesian equilibrium in which stochastic disruptions introduce instability in relationships, but the high wageeffort equilibrium can persist despite frequent firm shutdowns. The intuitive idea is that both firms and workers prefer to contract with their incumbent partners, ${ }^{9}$ but workers temporarily laid off by a shutdown will accept offers from non-incumbent firms, put in high effort, and treat the new employer as its incumbent firm if rehired.

\footnotetext{
Footnote 6 (continued)

1988; Croson 1996; Palfrey and Prisbrey 1997) suggesting that these temporary shutdowns could hurt the market if they result in random firm-worker rematching.

7 As opposed to recessions, where shocks are correlated.

8 Three other experimental papers also feature stochastic outcomes in a relational contract setup. Fehr and Zehnder (2009) incorporated shocks in the borrowers' ability to pay back loans in a credit market, Renner and Tyran (2004) experimented on one-time shocks to firms' production costs, and Bartling et al. (2018) extended the BFF setting to one where productivity is a noisy function of worker effort. As far as we know, we are the first to test the impact of direct shocks on the trading partner's ability to contract.

${ }^{9}$ In other words, their latest contracting partner.
} 
Because laid-off workers are seen as unemployed through no fault of their own, ${ }^{10}$ they are desirable to unmatched firms who poach these workers during shutdowns, leaving previously matched firms in need of new workers. ${ }^{11}$ This creates opportunities to build new relational contracts much later in the experimental periods than in markets without shutdowns. ${ }^{12}$

Our experiment finds that exogenous shutdowns destabilize matches, but, remarkably, high efficiency is maintained as firms and workers adapt their strategies. In our benchmark No Shutdowns condition, our results replicate BFF's findings: firms quickly become matched with workers and then rely on immediately renewing offers to the same workers as long as they did not shirk. However, as shutdowns increase in frequency, renewals between incumbent firm-worker pairs went down from $61 \%$ of market activity (No Shutdowns) to $47 \%$ (Frequent), while contracts between new pairs went up from 17 to $36 \%$. In spite of this instability, market efficiency is maintained across treatments with the exception of the last few periods. We see evidence that one firm's misfortune is another firm's opportunity: a worker is more likely to receive a private job offer from a new firm when his incumbent firm is temporarily shut down. ${ }^{13}$ Instead of treating these new offers as temporary side gigs, workers work just as hard (if not harder) for their wages indicating their desire to make a good impression. Aware of these fluid loyalties, firms returning after shutdowns are less likely to recall previous workers that have been actively working for others. This leads to relational instability without loss of market efficiency.

Overall, we see that relational contracts are robust to stochastic disruptions. Underneath it is a remarkable adaptability of firms and workers, who, given enough freedom, appear to reliably invent new strategies and norms that allow business to proceed even in the most difficult environments. ${ }^{14}$ Consistent with Davis and Haltiwanger's (1992) 'cleansing' effect, the shock destroyed many inefficient matches while leaving efficient matches mostly unharmed. While contracts between highearning workers and high-earning firms were similar across treatments, contracts between low-earning pairs were replaced by interactions between high-earners and low-earners. Overall, these disruptions have significant welfare effects. Workers cede more of their share of the trade surplus to firms (from 56 to 47\%), and

\footnotetext{
10 A similar effect occurs in volunteering, in which stochastic shutdowns provide an excuse for volunteers to quit without shame (Linardi and McConnell 2011).

11 A recent survey found that about $25 \%$ of furloughed workers, and about $67 \%$ of laid-off restaurant workers are not expected to return to their former employer if given an opportunity (see https://www. qsrmagazine.com/employee-management/will-employees-actually-return-restaurants).

12 This may be related to the 'restart' effect in public goods experiments, where contributions that had decreased to a low level jumped back up when the game was unexpectedly restarted (Andreoni 1988; Andreoni and Croson 2008; Chaudhuri 2018).

13 We see no increase in the likelihood of a public offer, suggesting that this is targeted-not indiscriminate-recruitment.

14 Adaptability appears to be a key factor in the robustness of relational contracts. Bernard et al. (2018) found that efficiency suffered when restrictions (such as fixed-partner and pay cut restrictions) were introduced, suggesting that free sorting /matching is key. Macchiavello and Morjaria (2015)'s empirical study of Kenyan rose growers and foreign-cut rose buyers find that relational contracts adapt to accommodate (localized and exogenous) supply chain disruptions due to ethnic violence.
} 
within-worker inequality grew. This echoes Lazear et al.'s (2016) and Cajner et al.'s (2020) findings: workers, particularly those that can least afford to take a hit, are those who suffer most when shocks hit real-life labor markets.

The rest of the paper proceeds as follows. In Sect. 2 we provide a theoretical model of the impact of stochastic shutdowns on contracting, with implications that are later tested by data from the experiments. Section 3 describes the experimental design. Section 4 discusses results. Section 5 is a short conclusion.

\section{Theoretical model}

In this gift exchange game let $[w, \tilde{e}]$ denote the wage $w \in[0,100]$ and desired effort level $\tilde{e} \in[1,10]$ in a contract offered by an employer. ${ }^{15}$ A worker who accepts the contract then chooses an actual effort level $e \in[1,10]$ with effort cost function $c(e)$. Unemployed workers receive unemployment pay of 5 .

The monetary payoff of an employer is:

$$
\pi(w, e)= \begin{cases}10 e-w & \text { if the offer is accepted } \\ 0 & \text { otherwise }\end{cases}
$$

The monetary payoff to the worker is:

$$
v(w, e)= \begin{cases}w-c(e) & \text { if the offer is accepted } \\ 5 & \text { otherwise }\end{cases}
$$

Let $\hat{w}(\tilde{e})=[10 \tilde{e}+c(\tilde{e})] / 2$ denote a fair wage offer -- one that offers an equal (or better) split of surplus. For desired effort $\tilde{e}$ and cost function $c(e)$, the corresponding schedule of fair wages is given below:

\begin{tabular}{lllllllllll}
\hline$\tilde{e}$ & 1 & 2 & 3 & 4 & 5 & 6 & 7 & 8 & 9 & 10 \\
$c(e)$ & 0 & 1 & 2 & 4 & 6 & 8 & 10 & 12 & 15 & 18 \\
$\hat{w}(\tilde{e})$ & 5 & 10.5 & 16 & 22 & 28 & 34 & 40 & 46 & 52.5 & 59 \\
\hline
\end{tabular}

Let there be two types of workers, selfish workers and fair workers. A worker is fair with probability $p \in(0,1)$. Utility of a selfish worker is just his monetary payoff:

$$
u(w, e)=v(w, e)
$$

The utility of a fair worker offered a contract of $(w, \tilde{e})$ and delivering $e$ is:

$$
u(w, e)= \begin{cases}v(w, e) & w<\hat{w}(\tilde{e}) \\ v(w, e)-b \cdot \max (\tilde{e}-e, 0) & w \geq \hat{w}(\tilde{e})\end{cases}
$$

\footnotetext{
${ }^{15}$ In this paper we will use the term employer and firm interchangeably.
} 
where disutility $b$ of not fulfilling a fair contract is assumed to be high enough such that a fair worker will always provide the requested effort if he accepts a fair contract.

We start by considering a one-period version of the game with $F \geq 2$ firms and $W>F$ workers. Firms can post offers of $(w, e)$ publicly or send it privately to a particular worker. A worker can only accept one offer per period: his employment status is displayed publicly so firms do not waste offers on workers that cannot accept it.

Let $p$ denote the fraction of workers who are fair. We show that if $p$ is high enough, there is a Perfect Bayesian Equilibrium where firms will offer a fair contract for non-minimal effort levels and fair workers will not deliver effort below what is requested (i.e shirk).

Proposition 1 The following is a Perfect Bayesian Equilibrium: firms will send public offers of $\hat{w}(\tilde{e})$ where the level of effort that can be achieved in the market, $\tilde{e}$, depends on p according to the schedule below. Fair workers will perform $e=\tilde{e}$ while selfish workers perform $e=1$.

$$
\begin{array}{cc}
p<0.55 & \tilde{e}=1 \\
0.55 \leq p<0.6 & \tilde{e}=2 \\
0.6 \leq p<0.65 & 3 \leq \tilde{e} \leq 8 \\
p \geq 0.65 & 8 \leq \tilde{e} \leq 10
\end{array}
$$

Extending the intuition to a game of $T$ periods (without shutdowns), let us make several assumptions. There exists at least the minimum proportion of fair types necessary to sustain non-minimum effort, which by Proposition 1 is $p=0.55$. Firms think all workers that shirk are selfish types, and will either not hire them or offer only a minimum contract $(5,1)$. Both sides of the market prefer to contract with incumbents: all else equal, a worker at period $t$ prefers to accept a contract renewal with his firm from $t-1$ and an firm at period $t$ prefers to rehire her worker from period $t-1$.

Letting $V_{t}$ be the cumulative future payoff of a worker that does not shirk at period $t$ and $V_{t}^{\prime}$ be the one for workers that shirk at $t$, the equilibrium effort level is the maximum $\tilde{e}_{t}$ that solves:

$$
c\left(\tilde{e_{t}}\right) \leq V_{t}-V_{t}^{\prime}
$$

By Proposition 1 , for $p=0.55, \tilde{e_{T}}=2$, which means that $V_{T-1}=10.5$, the fair wage for $\tilde{e_{T}}=2$, and $V_{t}^{\prime}=5$, the wage offered to selfish types. Because $c\left(e_{T-1}^{\tilde{T}}\right) \leq 5.5$, $e_{T-1}^{\tilde{e}}=4$. Continuing the process we arrive at $\tilde{e}_{t}=10$ for all $t<T-1$.

In this Perfect Bayesian Equilibrium, at $t=1$ all $F$ firms will send identical public offers of $(59,10)$ which will be accepted by $F<W$ workers. Because workers that shirk are treated as selfish types, in equilibrium there is no shirking until the last period. This not only supports high effort levels until $T-1$, but also maintains matches made in the first period, resulting in permanent unemployment of $W-F$ workers. BFF's experimental evidence, while not as stark as their theoretical prediction, indeed shows the market segmenting early into a high-tier market (high-wage contracts, high effort, and long-term relationships) and a low-tier market (low-wage 
contracts, low effort, and short-term relationships), with few opportunities to transition between the two markets.

What would happen to this disciplining mechanism in a market with stochastic disruptions? Consider the case where with probability $\delta$, a firm experiences a publicly observable shutdown where they cannot hire for $k>0$ periods. Here, firms will enter the labor market in a staggered manner. Once they start hiring, they have to temporarily lay off workers when a shutdown is exogenously imposed. Workers that are laid off during these local public disruptions-similar to workers who were never employed - are not labeled as shirkers, and hence are recruited by firms that still need workers. By the time incumbent firms are back in operation, they may have to start over in the labor market, thus continuing the cycle of instability in firmworker pairings.

We now show that there is a Perfect Bayesian Equilibrium in which the higheffort equilibrium can be achieved even with the aforementioned instability in firmworker pairing (Proposition 3). To do that, we first derive the probability that an available worker - a worker who does not have an incumbent employer in the labor market—gets an offer from another firm, $r_{t}$ (Proposition 2). This probability is a function of the four conditions firms can be in at any period $t$ : shut down (not hiring), hiring for the first time $\left(\right.$ First $\left._{t}\right)$, operating normally $\left(\right.$ Renew $\left._{t}\right)$, or returning to operations after a shutdown $\left(\right.$ Return $\left._{t}\right) .{ }^{16}$

Proposition 2 The probability that an available worker gets an offer from a nonincumbent firm at period $t$ is a function of disruption probability $\delta$ and can be recursively determined by:

$$
r_{t}=\frac{\left(\text { Return }_{t} r_{t-1}+\text { First }_{t}\right) F}{W-\left(\text { Renew }_{t}-\text { Return }_{t}\left(1-r_{t-1}\right)\right) F}
$$

where

$$
r_{1}=\frac{(1-\delta) F}{W}
$$

In the case of a one-period shock $k=1, r_{t}$ simplifies to:

$$
r_{t}=\frac{(1-\delta)\left(\delta^{t-1}+\left(\delta-\delta^{t-1}\right) r_{t-1}\right) F}{W-(1-\delta)\left(1-\delta+\left(\delta-\delta^{t-1}\right)\left(1-r_{t-1}\right)\right) F}
$$

Proposition 3 The following strategies and beliefs constitute a Perfect Bayesian Equilibrium in which both fair and selfish workers perform requested effort in the table below in all non-final periods.

\footnotetext{
${ }^{16}$ In the case of a one-period shutdown, these four probabilities are $\delta$ (firm is inactive now), First $_{t}=\delta^{t-1}(1-\delta)$ (firm experienced $t-1$ shocks), Renew ${ }_{t}=(1-\delta)^{2}$ (firm was in market at $t-1$ and $t$ ), and Return $_{t}=1-$ First $_{t}-$ Renew $_{t}-\delta=(1-\delta)\left(\delta-\delta^{t-1}\right)$ (firm was shut down in $t-1$ but not in $t-2$ and $t$ ).
} 


\begin{tabular}{lllllll}
\hline$t$ & $\leq T-5$ & $T-4$ & $T-3$ & $T-2$ & $T-1$ & $T$ \\
\hline$\tilde{e}$ for $\delta=0$ & 10 & 10 & 10 & 10 & 4 & 2 \\
$\tilde{e}$ for $\delta=0.1$ & 10 & 10 & 10 & 9 & 4 & 3 \\
$\tilde{e}$ for $\delta=0.5$ & 10 & 9 & 6 & 4 & 2 \\
\hline
\end{tabular}

- At period T, active firms offer a contract according to the schedule in Proposition 1. Fair workers perform $e=\tilde{e}$ while selfish workers shirk (perform $e=1$ ).

- At period $t<T$, an active employer offers her incumbent worker $\hat{w}\left(\tilde{e}_{t}\right)$ that satisfies Eq. 1 if the worker has neither shirked nor contracted with another firm at $t-1$. If her incumbent worker has shirked or is no longer available, the firm offers the same contract to another available worker (workers with no incumbent employer in the market). If there are no available workers left, the firm offers $(5,1)$ to any worker.

- At period $t<T$, a worker with an incumbent firm accepts a contract renewal, performs requested effort with probability $1-\delta$ and is laid off due to his firm's shutdown with probability $\delta$. A laid-off worker receives and accepts an identical offer from another firm with probability $r_{t}$ and from that point forward considers the new firm the incumbent employer.

- At period $t=1,(1-\delta) F$ firms make public offers of $\hat{w}(10)$. Workers unmatched at $t=1$ become employed at period $t$ with probability $r_{t}$.

- Off-equilibrium beliefs: Firms assume all workers that shirk are selfish types. Firms also assume that a worker who accepts a non-incumbent firm's offer when his incumbent employer is in the labor market must have shirked. If there are no $\tilde{e}_{t}$ that satisfy the condition such that selfish types do not shirk, firms behave as if they are in a one period game.

The four sub-figures in Fig. 1 below provide simulation results illustrating the dynamics of new employment opportunities ( $r_{t}$, Eq. 2, left panel) and effort level at the last six periods ( $\tilde{e}_{t}$, Proposition 3 , right panel). ${ }^{17}$ We use our experimental setting of nine firms and ten workers in this simulation. The top panel illustrates the effect of shutdowns lasting one period $(k=1)$ while the bottom panel illustrates shutdowns that last three periods $(k=3)$, which we will use for the experiment. As the probability and length of shutdowns increases, two things happen: the window of opportunity for new relational contracts is extended into later periods, and the high-effort equilibrium unravels earlier.

\section{Testable implications}

Together, the propositions and the simulation results allow us to predict how firms and workers will adapt relational contracts such that high efficiency is possible even with exogenous, stochastic shutdowns. We summarize our predictions below and test them in the experiment described in the next section.

\footnotetext{
17 Effort can be sustained at the maximum (10) in all $t \leq T-5$ for the range of parameters used in the simulation.
} 
We will run two models. We will use Eq. 3 to get a big picture of treatment effects. The first two variables are the treatment (frequency of shutdowns $\delta_{j}$ ) and period marker. Last $5_{t j}$ is a binary variable that is 1 for the last 5 periods $(25<t \leq 30)$; Last $5 \cdot \delta_{t j}$ is the interaction with the frequency of shutdowns. We will then use Eq. 4 for more detailed exploration of time trends and the role of shutdowns. In Eq. 4 IsShutdown $n_{i t}$ is a binary variable that is 1 if worker $i$ 's incumbent employer is shut down in period $t . X_{i t j}$ is a shorthand for control variables, which includes all the variables in Eq. $3\left(\delta_{j}\right.$, Last $5_{t j}$, Last $\left.5 \cdot \delta_{t j}\right)$ as well as additional controls.

$$
\begin{gathered}
Y_{i t j}=a+b_{1} \delta_{j}+b_{2} \text { Period }_{t j}+b_{3} \text { Last }_{t j}+b_{4}{\text { Last } 5 \cdot \delta_{t j}} \\
Y_{i t j}=a+b_{1} \text { Period }_{t j}+b_{2} \text { Period } \delta_{t j}+b_{3} \text { IsShutdown }_{i t j}+\gamma X_{i t j}
\end{gathered}
$$

1. Frequent shutdowns cause instability in relationships: As $\delta$ increases, the fraction of contracts with incumbent employers will decrease while the fraction of contracts with new employers will increase.

Let Incumbent $_{i t j}$ be a binary variable that indicates that worker $i$ in period $t$ in session $j$ contracted with an incumbent and $N e w_{i t j}$ be a similar variable indicating a contract with a new employer. Running the regression in Eq. 3 with $Y_{i t j}=$ Incumbent $_{i t j}$ we predict that $b_{1}<0$. Conversely, when $Y_{i t j}=N e w_{i t j}, b_{1}>0$.

2. With the exception of the last few periods, market efficiency is unharmed: According to Proposition 3, though the market unravels earlier, market efficiency (proxied by workers' effort $)^{18}$ and the wages supporting it will be the same across treatments.

Let Effort $_{i t j}$ be the effort level delivered by worker $i$ in period $t$ in session $j$ and Wage $_{i t j}$ be the corresponding wage. When we regress $E$ ffort $t_{i t j}$ on Eq. 3, we predict $b_{1}=0$ while $b_{4}<0$. The same is predicted for Wage W $_{i j}$.

3. Shutdowns prolong invitations to start new relational contracts: As shown in the left panel of Fig. 1, the probability that a worker gets an offer from a new firm decreases with time, disciplining workers against shirking. However, as temporary shutdowns become more frequent, this decline becomes less pronounced.

Let $N e w O f f e r_{i t j}$ be a binary variable that is 1 if worker $i$ receive a private offer from a new firm at period $t$. When we regress $N e w O f f e r_{i t j}$ on Eq. $4, b_{1}<0$ and $b_{2}>0$.

4. Shutdowns provide direct opportunities for poaching: Workers are assumed to prefer their incumbent firm, and hence are seen as more available during their firms' shutdown. Therefore, when we regress $N e w O f f e r_{i t j}$ on Eq. 4 , we expect $b_{3}$ to be positive.

\footnotetext{
${ }^{18}$ Market efficiency is the surplus generated by a trade compared to the maximum possible surplus: $[10 e-c(e)] /\left[10 e_{\max }-c\left(e_{\max }\right)\right]$ where $e_{\max }=10$. Since surplus is a function of effort only, effort in itself is a sufficient proxy for efficiency.
} 

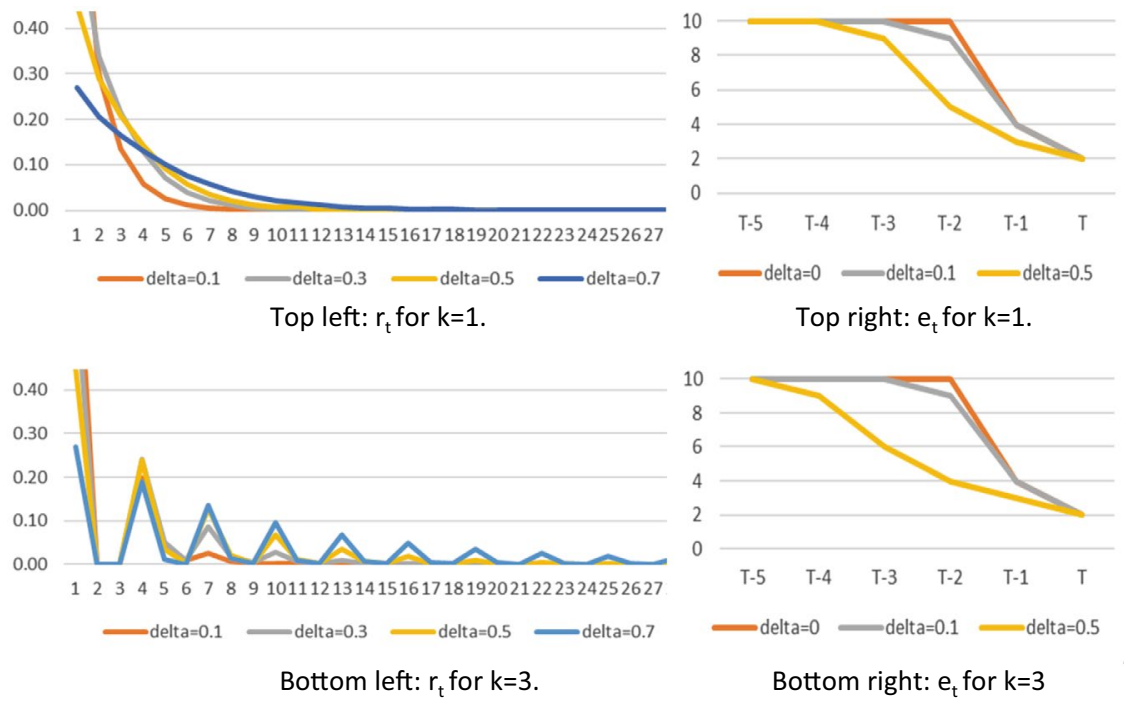

Bottom right: $e_{t}$ for $k=3$

Fig. 1 Simulation of $r_{t}$ and $\tilde{e_{t}}$ for $k=1$ and 3 and $\delta=0$ to 0.7

Similarly, a worker is less likely to be rehired by his former employer after a shutdown if he has been employed elsewhere extensively in the meantime. Looking only at periods where a worker's incumbent firm is returning from a shutdown, let Rehire $_{i t j}$ be a binary variable that is 1 if worker $i$ 's returning employer sends him a private offer and \#Contracts itj $_{j}$ be the number of periods $i$ worked for another firm during the shutdown. Regressing the former against the latter (Eq. 4), we predict the coefficient on \# Contracts itj $_{\text {w }}$ will be negative.

5. Contracts during shutdowns are not "McJobs" but attempts at longer term relational contracts: Poaching firms make fair, high wage offers to laid-off workers and laid-off workers do not shirk. Regressing $W_{a g} e_{i j j}$ against Eq. 4, we predict $b_{3}=0$. The same is predicted for Effort $_{i t j}$.

\section{Experimental design}

All sessions consist of nine firms and ten workers who traded for 30 periods. ${ }^{19} \mathrm{We}$ utilize a large number of firms and workers in order to have enough firms to contract during periods of shutdowns. We implemented three treatments to test the robustness of relational contracts to exogenous, stochastic disruption: No Shutdowns, our baseline treatment where there are no exogenous disruptions $(\delta=0)$; Infrequent shutdowns where in each period, a firm may be forced to shut down operations for

\footnotetext{
${ }^{19}$ Except for one $\delta=0.5$ session where we had eighteen subjects and hence ran with nine firms and nine workers. While there is little power to test whether this session produced different results than the other four, there are no substantive differences so all sessions were pooled in our analyses.
} 
three periods with probability $\delta=0.10$, and Frequent shutdowns where the probability of this firm-specific shock is 0.50 . The length and probability of shutdowns are common knowledge among all subjects.

Our No Shutdowns sessions are a replication of BFF's incomplete contract condition with reputation formation. This is a finitely repeated game where firms and workers are assigned a fixed identification number that will persist for the entire game. All workers' employment information is publicly available to all firms for each period. Firms make contract offers, specifying wages $\left(w_{t}\right)$ and desired effort level $\left(\tilde{e}_{t}\right)$. A firm can offer the same contracts to all workers simultaneously using a publicly posted offer, which is observable to everyone in the market (including other employers). A firm can also address her offer to a specific worker using private contracts sent to the worker's ID. ${ }^{20}$

A firm can make as many offers as she desires, but can only contract with one worker in each period. A worker cannot make offers, but instead choose from a listing of all public offers and the private offers addressed to him. A worker can only accept one contract per period. ${ }^{21}$ After accepting a contract, the worker is publicly shown to be no longer available for hire. He then chooses the effort level he wants to deliver $\left(e_{t}\right)$, which does not have to abide by the effort level requested by the employer due to lack of third-party enforcement. The cost of effort and payoffs for both employers and workers, which follows the theoretical model in the previous section, are then displayed to both parties. ${ }^{22}$

Our Infrequent and Frequent shutdown treatments modeled idiosyncratic employer-specific shocks that exogenously interrupt relationships. ${ }^{23}$ As is often the case in the real world, the identities of the firms who are forced to shut down in the current round are public knowledge to all firms and workers. This has the additional benefit of eliminating a firm's strategic misreporting of her status. An inactive firm cannot make any offers (and hence has to "lay off" her incumbent worker), but is still able to observe the market and is therefore aware of other firms' public offers and of all workers' employment statuses.

We chose to implement a three-period shutdown $(k=3) .{ }^{24}$ This duration is short enough to have a small effect on payoffs, but long enough that a laid-off worker and his new employer (assuming he finds one) may develop a new relationship. For analytical tractability, we have modeled only the $k=1$ case in the theoretical section, but as illustrated by the simulation in Fig. 1 , the $k=3$ case is qualitatively similar.

The experiment was programmed and conducted with the $\mathrm{z}$-Tree software, based on BFF's original software. Figs. A1-3 in the "Appendix" in ESM provides a graphical timeline of the experiment using screenshots. Before the game started, subjects

\footnotetext{
${ }^{20}$ A screenshot of the firm's contracting screen can be seen in Fig. A1 in the "Appendix" in ESM.

21 The worker's screen can be seen in Fig. A2 in the "Appendix" in ESM.

22 The outcome screen can be seen in Fig. A3 in the "Appendix" in ESM.

23 https://www.cbsnews.com/news/coronavirus-restaurants-again-shutting-their-doors-as-coronaviru s-flares/. Note, however, that larger outbreaks may be better proxied by correlated shocks, which is outside of the scope of this paper.

${ }^{24}$ We employ thirty periods so that firms still have substantial time to contract even with a three-period shutdown duration.
} 
were given a quiz to ensure their understanding of the game and the payoffs to firms and workers. Each session lasted approximately $100 \mathrm{~min}$ and subjects earned, on average, \$35. We conducted 5 sessions of each treatment at the University of Pittsburgh. In the "Appendix" in ESM we include data from pilot experiments at the California Institute of Technology (Caltech) where subjects have substantial laboratory experience, and at University of California in Los Angeles (UCLA) which is representative of a more typical large-university student population. The Caltech sessions provide a comparison of $\delta=0$ and $\delta=0.05$, while the UCLA sessions include $\delta=0$ and $\delta=0.1$

\section{Results}

Our results section is organized as follows: Table 1 reports summary statistics at the session level with each session contributing one data point. We use two-sided Wilcoxon rank sum tests to test differences across treatments. Figure 2 plots the empirical time series of private offers from new firms $\left(r_{t}\right)$ and effort levels $\left(e_{t}\right)$ that were simulated in Fig. 1 (bottom panel, $k=3$ ). Tables 2, 3 and 4 present regressions testing the five testable implications from the theoretical model. Table 2 tests Hypotheses 1 and 2, Table 3 tests Hypotheses 3 and 4, while Table 4 tests Hypothesis 5. We use bootstrapped standard errors clustered at the session level for all regressions.

Table 1 shows the main features of the market. Contracts feature wage offers averaging 34.42-39.41, requested effort between 7.14-7.61, and delivered effort about one unit lower than the requested effort (6.21-6.64). ${ }^{25}$ Average wages are a little lower than the fair wages for the requested effort levels, but the actual effort delivered by workers generates a more equitable surplus. None of the differences were significant using a two-sided Wilcoxon rank sum test, suggesting that market efficiency was preserved.

Differences begin to emerge as we look closer at the nature of the contracts. Public wage offers and firms' propensity for private offers over public offers were similar across all treatments, but private wage offers were significantly lower in the Frequent treatment compared to the other two treatments (37.38 vs. 46.80 and 45.30 , $p<0.01)$. This may be due to the identity of the contracting partners. Compared to the No Shutdowns sessions, the Frequent sessions had fewer contracts between an employer and her incumbent worker ${ }^{26}(61 \%$ vs. $47 \%, p<0.10)$ and more contracts between new partners $(17 \%$ vs. $36 \%, p<0.01))$. The proportion of contracts between an employer and past workers was not affected by shutdown frequency.

This instability changes the nature of matching between firms and workers. In the No Shutdowns sessions, low-earning firms contract mostly with low-earning

\footnotetext{
25 Because effort is below the surplus-maximizing value of 10, market efficiency is around $66 \%$.

26 As a reminder the incumbent worker refers to the worker that a firm had contracted with in her most recent period of market activity.
} 
workers $(40 \%)^{27}$ - the same is true for high-earning firms and workers $(40 \%)$. However, in the Frequent shutdown treatment, contracts between low-earning firmworker pairs only make up $17 \%$ of the market, replaced with contracts between low earners and high earners $(47 \%){ }^{28}$ The increase in disruption frequency seems to have what Davis and Haltiwanger (1992) refer to as the cleansing effect of recession-rematching inefficient firm-worker pairs without harming those in efficient matches $(40 \%$ to $35 \%, p>0.10)$.

Workers appear to bear more of the weight of these stochastic disruptions. The share of the total surplus that goes to workers is lower in the Frequent treatment (56\%, compared to $47 \%$ in No Shutdowns, $p<0.01$ ). This is in line with Lazear et al.'s (2016) study of the 2008 recession which shows that maintained productivity was driven by workers doing more with less. Like Cajner et al.'s (2020) study of the impact of coronavirus, we also see that those that can least afford to take a hit are most harmed. With Frequent shutdowns, the top 20\% of workers increase their share of the total worker surplus from $43 \%$ to $55 \%$. The frequency of shutdowns does not appear to affect firm-side inequality.

Some time trends can be seen in Fig. 2. The left panel shows that opportunities to form new relational contracts - in the form of private offers from new firms-are mostly concentrated in the early periods in the No Shutdowns treatment, are shifted back several periods in the Infrequent shutdowns treatment, and finally are spread out throughout the periods with Frequent shutdowns. The right panel shows that delivered effort drifts up over time to a surprisingly similar degree across all treatments, starting around 5 units and increasing to 7.5 and before dropping in the last five periods to 6.5 (in No Shutdowns) or 5 (in the other two treatments).

We will now use regression analysis to test the five predictions presented earlier. A total of 2872 contracts were executed between 135 firms and 149 workers in 15 sessions of this 30-period game. Table 2 tests Prediction 1 and 2 with the regression in Eq. 3. $\delta$ is rescaled such that 1 corresponds to our Frequent treatment (where per-period probability of shutdown is 0.5$).{ }^{29}$ Period is also rescaled so that each unit corresponds to 10 periods.

As hypothesized in Prediction 1, we find that the coefficient for $\delta$ is negative for Column 1 and positive in Column 2. As shutdown frequency goes from 0 to 0.5 , workers are $13.8 \%(p<0.10)$ less likely to contract with an incumbent employer (note that we include firms returning from a shutdown here) and $32.3 \%$ more likely to contract with a completely new firm $(p<0.01)$.

\footnotetext{
27 For each experimental session, we first rank the 10 workers' earnings against each other, and then do the same for firms. We then calculate the number of times workers who are ranked in the top 50\% worked with firms who are in the top $50 \%$.

${ }^{28}$ Specifically, $36 \%$ of market contracts were from high earning workers contracting with low earning firms and $11 \%$ from low earning workers contracting with high earning firms. These percentages were $15 \%$ and $5 \%$, respectively, for the No Shutdown treatment.

29 Probability of shutdown in the Infrequent treatment is 0.1 .
} 
Table 1 Summary statistics

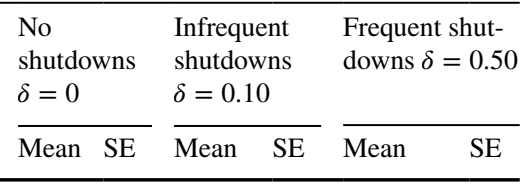

Market statistics

Wages offered by firms

$\begin{array}{llllll}38.99 & 1.96 & 39.41 & 2.59 & 34.42 & 3.72 \\ 7.69 & 0.13 & 7.92 & 0.31 & 7.47 & 0.47 \\ 6.21 & 0.24 & 6.64 & 0.40 & 6.25 & 0.64\end{array}$

Effort delivered by workers

Wages by offer types

Wages in public contracts

$\begin{array}{llllll}24.25 & 3.87 & 24.92 & 1.67 & 25.49 & 4.18 \\ 46.80 & 0.81 & 45.30 & 2.44 & 37.38 * * * & 3.10 \\ 0.64 & 0.05 & 0.71 & 0.03 & 0.68 & 0.09\end{array}$

$\%$ private offer

Identity of employer in contracts

Worker's incumbent employer

Worker's previous (but non-incumbent) employer

$\begin{array}{llllll}0.61 & 0.05 & 0.59 & 0.03 & 0.46^{*} & 0.06\end{array}$

A completely new firm

$\begin{array}{llllll}0.22 & 0.04 & 0.19 & 0.03 & 0.17 & 0.03\end{array}$

$\begin{array}{llllll}0.17 & 0.01 & 0.22 & 0.01 & 0.36 * * * & 0.03\end{array}$

\section{Matching}

Bottom 50\% workers with bottom 50\% firms

$\begin{array}{llllll}0.40 & 0.01 & 0.29 * * & 0.02 & 0.18 * * * & 0.05 \\ 0.20 & 0.03 & 0.34 * * & 0.04 & 0.47 * * & 0.09 \\ 0.40 & 0.02 & 0.37 & 0.02 & 0.35 & 0.04\end{array}$

Top 50\% workers with top $50 \%$ firms

Welfare

Workers' share of total surplus

$\begin{array}{llllll}0.56 & 0.01 & 0.52 & 0.02 & 0.47 * * * & 0.01 \\ 0.43 & 0.02 & 0.47 & 0.02 & 0.55 * * * & 0.02 \\ 0.38 & 0.01 & 0.34 & 0.02 & 0.38 & 0.05 \\ 1323 & & 1026 & & 523 & \\ 1500 & & 1500 & & 1470 & \\ 5 & & 5 & & 5 & \end{array}$

Top 20\% workers' share of worker surplus

Top 20\% firms' share of firm surplus

Number of contracts

Number of worker-period (including unemployed periods)

$\mathrm{N}$ (number of markets)

Wilcoxon test of treatment differences from $\delta=0$

$$
* * * p<0.01, * * p<0.05, * p<0.1
$$
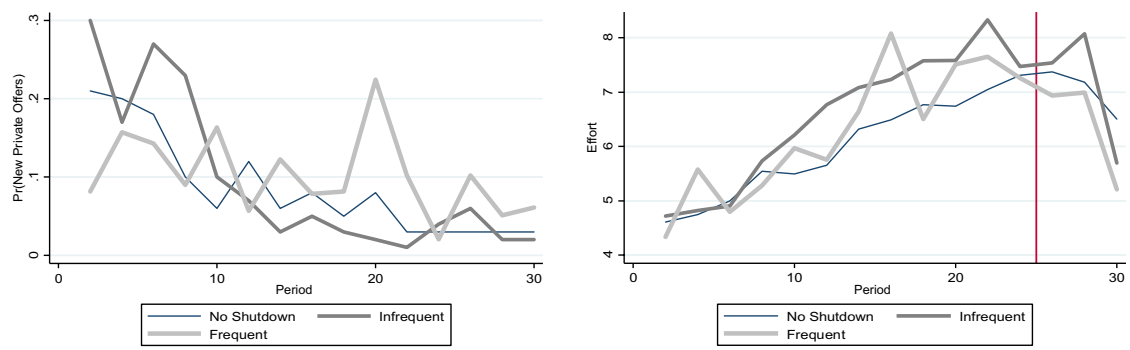

Fig. 2 Empirical distribution of $\mathrm{r}_{\mathrm{t}}$ (left) and $\mathrm{e}_{\mathrm{t}}$ (right) for $\mathrm{k}=3$ and $\delta=0-0.5$. Note: Distribution was smoothed by binning per-period session averages over 2 periods 
Table 2 Increased disruptions $(\delta)$ cause instability in contracting partners (Column 1 and 2) but does not decrease market efficiency (Column 3)

\begin{tabular}{lllll}
\hline Variables & $(1)$ & $(2)$ & $(3)$ & $(4)$ \\
& $\begin{array}{l}\text { Contracted with } \\
\text { Incumbent employer }=1\end{array}$ & $\begin{array}{l}\text { Contracted with } \\
\text { new firm }=1\end{array}$ & $\begin{array}{l}\text { Effort delivered } \\
\text { Wage offered }\end{array}$ & \\
\hline$\delta$ (per 0.50) & $-0.138^{*}$ & $0.210^{* * *}$ & 0.187 & -4.443 \\
& $(0.071)$ & $(0.036)$ & $(0.712)$ & $(4.248)$ \\
Period (per 10) & $0.273^{* * *}$ & $-0.323^{* * *}$ & $1.279 * * *$ & $5.204 * * *$ \\
& $(0.020)$ & $(0.010)$ & $(0.155)$ & $(0.997)$ \\
Last 5 Periods & $-0.178^{* * *}$ & $0.281^{* * *}$ & $-1.081^{* * *}$ & $-2.155^{* *}$ \\
& $(0.024)$ & $(0.017)$ & $(0.173)$ & $(0.917)$ \\
Last 5 $\delta$ & -0.084 & -0.043 & $-0.993^{* *}$ & -1.442 \\
& $(0.056)$ & $(0.050)$ & $(0.413)$ & $(3.301)$ \\
Constant & $0.219 * * *$ & $0.629 * * *$ & $4.569 * * *$ & $31.837 * * *$ \\
& $(0.037)$ & $(0.020)$ & $(0.376)$ & $(2.850)$ \\
Observations & 2872 & 2872 & 2872 & 2872 \\
R-squared & 0.170 & 0.325 & 0.071 & 0.055 \\
\hline
\end{tabular}

Bootstrapped standard errors (50 replications) in parentheses clustered at the session level (15 sessions) $* * * p<0.01, * * p<0.05, * p<0.1$

Result 1: Frequent shutdowns cause instability in relationships Shutdowns do not merely postpone contracts between existing partners but makes them less likely to recur, necessitating the creation of new relationships.

Interestingly, this instability does not lead to market inefficiency. Column 3 shows that increasing disruption frequency did not lower delivered effort $(0.187, p>0.10)$ beyond the last few periods. Beyond the standard end game effect on delivered effort Last5Periods $(-1.081, p<0.01)$, we see an additional drop in the interaction term Last $5 \cdot \delta(-0.993, p<0.05)$ due to the earlier unraveling introduced by increasing $\delta$. Wages are slightly lower in the Frequent shutdowns sessions than in the No Shutdowns sessions but the difference is not significant (Column 4$).{ }^{30}$ There are no additional drops in wages for the last five periods, suggesting that firms did not anticipate that the market would unravel earlier.

Result 2 Frequent shutdowns cause the market to unravel earlier, but do not otherwise decrease market efficiency.

Before moving on to Result 3, we note that the coefficients on Period in Table 2 provide some initial insight into the time trends in contracting. As the game progresses, workers are much more likely to contract with an incumbent firm (Column

\footnotetext{
${ }^{30}$ We see no evidence that firms provide de-facto unemployment insurance (Azariadis (1975), Rute Rute Cardoso and Portela (2009)) in this setting.
} 


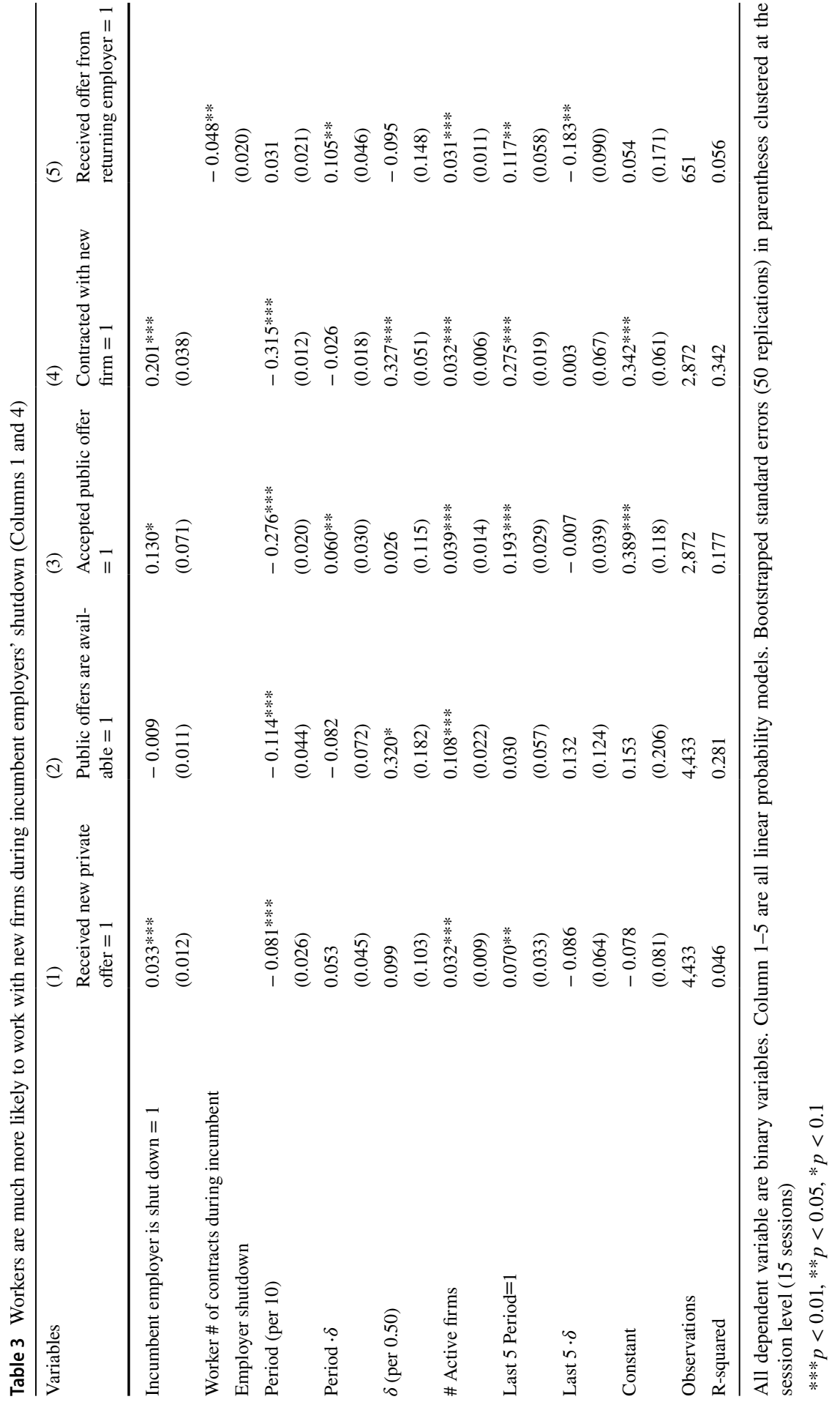


$\frac{\bar{d}}{\frac{\pi}{2}}$

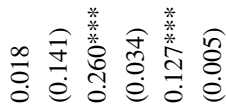

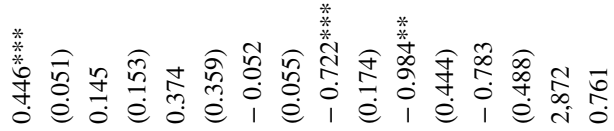

:

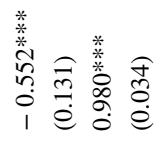

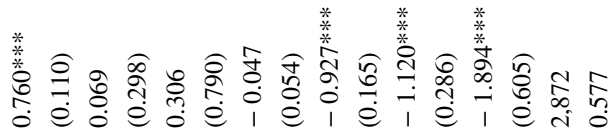

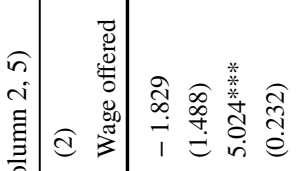

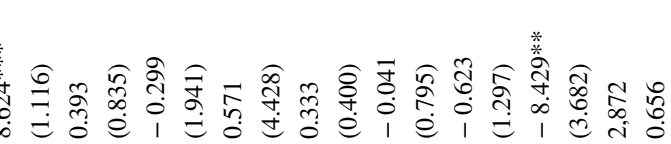

0
0
0
0
0
0
0
0
0
0
0
0
0
0
0
0
0
0
0
0
0
0
0
0
0

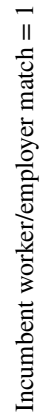

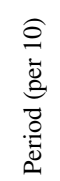

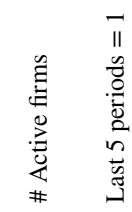

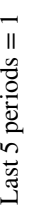


$1,0.273$ ) and much less likely to continue experimenting with new firms (Column $2,-0.323)$. Every 10 periods of the game correspond to a 1.279 point increase in effort (Column 3) which is supported by a 5.204 raise in wages (Column 4).

Table 3 explores how shutdown frequency and the shutdowns themselves change the dynamics of work opportunities. To do this, we need to look at periods where workers did not work as well as those where they did. We therefore switch from using contracts as the unit of observation to worker-period (149 workers $\times 30$ period $=4470$ worker-periods). Because the shutdown "knocks out" firms for several periods, as in real-world labor market shocks, we include \#ActiveFirms to control for the number of firms that are able to make offers. ${ }^{31}$

The coefficients in Period in Table 3 Column 1 shows that the probability that a player will get an offer from a new firm decreases by $8.1 \%(p<0.01)$ every 10 periods in No Shutdowns. ${ }^{32}$ The evidence on whether $\delta$ slows down the decline of new private offers is mixed. The coefficient on Period $\cdot \delta_{j}$ is not significant, but it is positive $(5.3 \%, p>0.10)$ and the linear combination of Period and Period $\cdot \delta_{j}$ is no longer significantly positive $(2.8 \%, p>0.10)$.

Result 3 There is no significant difference in the time trend of new private offers due to the frequency of shutdowns, however, the significant decline seen in the No Shutdown treatment is smaller in magnitude and not significant in the Frequent shutdown treatment..

Now let us look directly at the role of shutdowns. Our focus is the binary variable IsShutDown (shown in Tables 3 and 4 as "Incumbent Employer is Shut Down") which is 1 when the worker's incumbent employer is forced to shut down. Column 1 shows that workers are $3.3 \%$ more likely to get a private offer from new firms in each period of the shutdown $(p<0.01)$. Given that the average per-period probability that a worker receives a private offer from a new firm is only $9 \%$, this is a substantial increase. It appears that firms notice suddenly-unemployed workers and try to "poach" them with new offers. ${ }^{33}$ Regressing the availability of public offers against IsShutDown in Column 2, we see that firms are not more likely to send indiscriminate public offers during other firms' shutdowns, confirming their intention to target specific workers. However, anxious workers without good private offers are more likely to accept whatever public offer is available (Column 3). As a result of this combination of firm poaching and laid off workers' decreased selectivity, new matches are being formed during shutdowns (Column 4).

How does the incumbent employer react upon return to operations? Our model describes an equilibrium where all agents prefer to continue contracting with

\footnotetext{
31 Demand for labor, i.e the ratio of firms to workers across all periods (after accounting for the shutdowns), is 0.45 for $\delta=0.50,0.81$ for $\delta=0.10$, and 0.90 for $\delta=0$. Brown et al. found that relational contracts persist under different firm-worker ratios, even when there is excess demand for labor rather than excess supply of labor.

32 We see that availability of public offers (Column 2) and the probability that a worker will accept public offers (Column 3) also decrease in time.

${ }^{33}$ Recall that the experimental setup includes a screen where firms can see worker availability.
} 
whoever they contracted with last, supported by off-equilibrium beliefs that workers that do not do so have shirked. This implies that a firm that is returning from a shutdown is reluctant to reconnect with workers who worked for other firms, since they are no longer the worker's incumbent employer. The coefficient on \#Contracts (shown in Table 3 as "Worker \# of Contracts During Incumbent Employer Shutdown") in Column 5 indeed shows that for every contract the worker engages in during the shutdown, his incumbent firm is $4.8 \%$ less likely to offer to rehire him upon her return to operation.

Result 4 Shutdown periods provide direct opportunities for poaching. Firms let go of poached workers.

Finally, Table 4 investigates the intention behind the demand and supply for labor of laid-off workers. ${ }^{34}$ We earlier hypothesized that as the frequency of shutdowns increases, the probability that firms become disconnected from incumbent workers increases, and with it, the need to build new relational contracts. Since layoffs are not related to performance, laid-off workers are not stigmatized as shirkers and are seen as potential long-term hires for these firms. This implies that wages offered to laid-off workers are likely to be fair, as opposed to the minimum wages offered to shirkers. Similarly, we hypothesize that laid-off workers are not just waiting for their incumbent employer to return and rehire them-instead, they are actively looking for new relational contracts. This implies that they will not treat the job as "temping" and instead will put in good effort in hopes that it will turn into something more long term.

Table 4 Column 1 shows that contrary to our hypothesis, wage offers to laid-off workers are actually 4.5 points lower $(p<0.01)$ than wages to non-laid-off workers. Column 2 explains why: firms pay a significant wage premium to incumbent workers (8.624), which is not offered to new hires by definition. After controlling for the incumbent premium, there are no longer any difference between wages offered to laid-off workers and wages offered to other workers.

We find the same phenomenon for effort. Without controlling for lower wages, we find that effort expended by laid-off workers is 0.5 lower than that of non-laid-off workers (Column 3), however, this difference disappears after controlling for lower wages (Column 4). In fact, laid-off workers actually work harder (Column 5) after controlling for the effect of incumbent matches on delivered effort. It turns out that workers, like firms, also provide a bonus to incumbents. After controlling for this, we find that workers are actually working harder with less when they are laid off, anxious to secure themselves another position.

Result 5: Shutdown periods are used to explore new relational contracts Poaching firms make fair, high wage offers and laid-off workers do not shirk.

\footnotetext{
${ }^{34}$ Contracts involving laid off workers -i.e the workers left behind by their incumbent firms' shutdownmake up $0 \%, 6 \%, 31 \%$ of market activity in, respectively, No Shutdowns, Infrequent, and Frequent treatments.
} 
Figure 3 graphically illustrates how relational contracts adapt to stochastic disruptions. ${ }^{35}$ Each panel documents the contracting experience of a single worker. The $\mathrm{x}$-axis marks the periods while the $\mathrm{y}$-axis sorts the worker's employers by his frequency of contracts with that employer. For example, Employer 1 is the firm for whom the worker works in the most periods. We identify firms by their experimental subject ID number shown in the graph. For example, for the worker in the Top left panel's Employer 1 is Firm 1901 and the worker works by far the most periods for that firm. Marker sizes indicate the effort delivered by the worker in that particular period. There are three types of markers: a hollow circle indicates a regular contract, a filled circle is a worker's first contract during his incumbent employer's shutdown, and a diamond shows that the worker is rehired after the incumbent firm recovers.

Without exogenous disruptions, firms and workers quickly settle in a single, continuous relational contract after a short period of experimentation. For example, the top left panel of Fig. 3 shows worker 1903 settling down with firm 1901 after trying out firm 1902 and 1909. This basic pattern of contracting changes very little with Infrequent shutdowns. Worker 1701 in the top right panel provides a typical example. This worker settles down with firm 1707 early on and waits out shutdowns by taking low-paying, low-effort jobs (see small filled circles labeled with firm 1701 and 1706). When firm 1707 returns to operation, the worker is rehired and their relationship continues as before (see large diamond followed by large hollow circles).

Frequent shutdowns, on the other hand, fundamentally change the pattern of relational contracts from one where a worker finds stable employment from one firm to one where he juggles multiple employers. The bottom row of Fig. 3 provides two examples. On the left we see a worker who gradually shifted away from his primary employer after a shutdown. Worker 3401 started with firm 3403, but worked extensively for firm 3404 during firm 3403's shutdown. He eventually put in high effort only for 3404 and shirked whenever hired by his former employer. The right panel depicts worker 3408 who balances three relational contracts at a time (with firms 3402,3405 , and 3401). The worker ends up working with 5 firms in total, with a career path that resembles a freelancer rather than an employee.

\section{Conclusion}

These experiments explore the robustness of gift-exchange markets to a realistic kind of interruption. In these markets firms offer an enforceable wage and request unenforceable effort from workers. Effort is costly for workers and valuable for firms; surplus is created if workers accept jobs and choose to deliver high effort. Because the cost and benefits of wages net to zero, efficiency depends entirely on total worker effort.

Previous experiments have shown that efficiency can be quite high, especially when workers are identifiable and employers can repeatedly contract by making private worker-specific offers. These are relational contracts because employers request

35 The figures here show a sample of workers who are among the top $20 \%$ of earners in their session. 


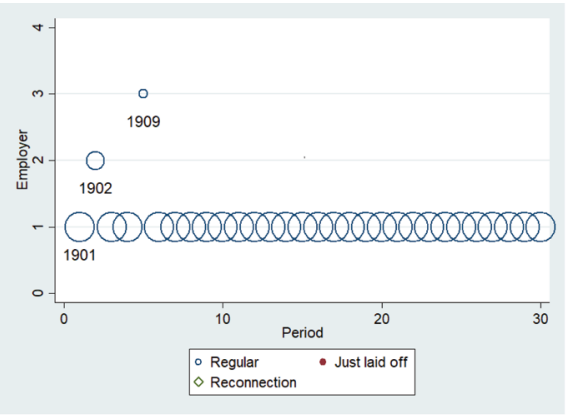

Top left: Worker 1903 (No Shutdown).

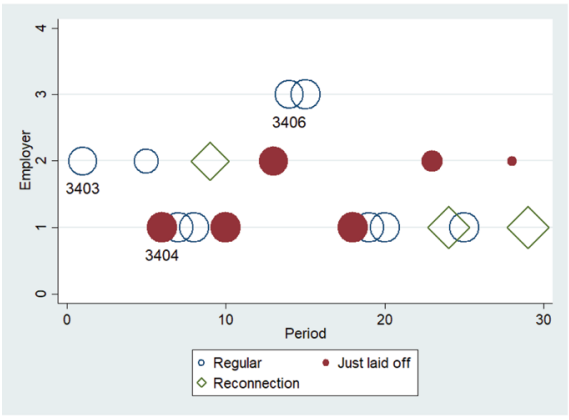

Bottom left: Worker 3401 (Frequent)

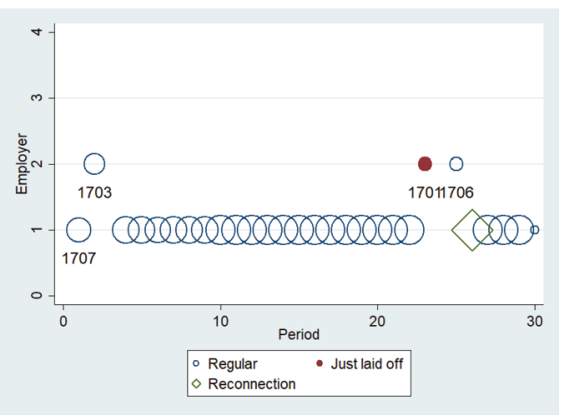

Top right: Worker 1701 (Infrequent).

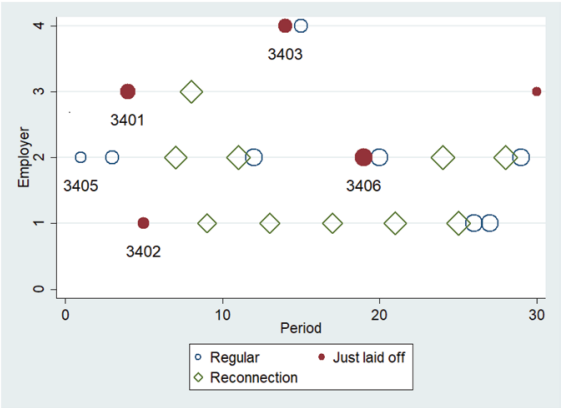

Bottom right: Worker 3408 (Frequent)

Fig. 3 Workers' contracting patterns across the three experimental treatments. Note: A hollow circle indicates a regular contract, a filled circle is a worker's first contract during his incumbent's shutdown, and a diamond shows that the worker is rehired after the incumbent firm recovers. Gaps between markers indicate worker was not employed in that period. Effort $=$ size of marker. Employer numbers are sorted by frequency of contracts with worker. For example, Employer 1 is the employer for whom the worker works in the most periods. Employer number is the experimental subject ID number shown in the graph. For example, for the worker in the Top left panel's Employer 1 is Firm 1901 and the worker works by far the most periods for that employer

effort but depend on the worker to deliver the appropriate level of effort and there is worker moral hazard because direct pay does not depend on effort alone.

The key experimental treatment we use is a change in the probability with which firms suffer a firm-specific three-period disruption and cannot hire workers. (The COVID-19 pandemic is a magnified example of this on a massive and worldwide scale.) Many other types of disruptions could be simulated through experimental design. The short-run disruptions to firms' labor demand we study here is just a starting point for an experimental program of understanding robustness to various other kinds of shocks, especially the business-cycle effects of correlated shocks.

In earlier experiments, relational contracts typically form when an employer first hires a worker, then renews his contract privately if the worker does not shirk. Wages and effort increase and market-wide efficiency is high. Shutdowns pose a challenge to this efficient regime of relational contracting by exogenously breaking 
such contracts. In this paper we present a theory in which firms challenged by this downturn navigate through selfish, strategic workers, who co-exist with fair-minded ones (who always provide the requested level of effort), and manage to maintain high equilibrium. This model has several testable implications. General patterns in the data are consistent with these predictions. We see that shutdowns cause instability in the form of random rematching, but do not affect workers' effort beyond the last few periods. We find that the shutdown periods provide a direct opportunity for firms to try out new workers, since laid-off workers are uncertain about being rehired by their incumbent firms and seek to make a good impression to other firms. We also observe that workers' suffer more from these disruptions, which was not predicted by our model but is consistent with empirical research on recessions.

We conclude with several remarks. First, the statistical power to identify differences across $\delta$ conditions is limited. As is well-known in experimental economics, the error structure in observations from individuals and periods in complicated markets are complicated to analyze (e.g. Fréchette 2012). A conservative way to treat these data is to use one experimental session as a single observation (see Table 1). Nonetheless, the main observations in these 15 sessions were also evident in a large number of sessions in two previous student subject pools. ${ }^{36}$

Second, it is always the case that these markets have "McJobs" equilibria in which firms' expectation that all workers will completely shirk leads to the lowest profitable wage offer, which in turn leads to low efficiency. In this paper we present a theoretical model predicting minimal harm to market equilibrium. However, it is also quite possible that exogenous disruptions could inject enough strategic uncertainty to undermine formation of relational contracts and market efficiency. Observing these markets achieve substantial efficiency taught us that these markets are surprisingly resilient to exogenous interruptions. The power of rematching of involuntarily-unemployed workers creates something closely akin to the "restart" effect in public goods experiments.

Finally, during the extreme condition with $\delta=.5$, firms were often in downturns, creating involuntary unemployment among workers. As a result, a large number of subjects-both firms and workers-in those experimental sessions were visibly bored and not very happy. It has been known for a long time that unemployment is bad for mental health (Eisenberg and Lazarsfeld 1938; Paul and Moser 2009) and causes a host of other negative social outcomes. Unemployment strongly reduces measured subjective well-being (Di Tella et al. 2001; Kahneman and Krueger 2006) and negative effects can be long-lasting (Lucas et al. 2004). Similarly, successful relational contracting between pairs of people may generate a sense of social closeness, camaraderie, and endogenous group affiliation or empathy (what Adam Smith called fellow-feeling). Observing our subjects' reaction to this experimental labor market suggests that this paradigm could conceivably be used to study the

\footnotetext{
36 These data are treated as pilots and reported only in an "Appendix" in ESM. Stochastic disruptions do not harm the high equilibrium ("Appendix" Table A1 in ESM), terminate the relationship of less optimal employer-worker pairs ("Appendix" Table A2 in ESM), and improve the short-term market ("Appendix" Figs. A5-8 in ESM).
} 
psychology and even consequences of such effects. Experimental observation of these psychological and emotional forces could be achieved by combining the usual observations of choice and effort with self-reports and biological measures. Such measures, combined with theory, could bring more scientific precision to concepts that are often relegated to areas of public health or organizational psychology and are important, but not present in most economic contracting models (cf. Brandts et al. 2014 on legitimacy).

\section{Theoretical appendix}

\section{Proposition 1}

Proof Since there are no future periods, $1-p$ selfish workers would shirk no matter what wage is offered. Employers are restricted to fair wages $\hat{w}(\tilde{e})$ if they want to get beyond minimum effort from the $p$ fair workers. Since there is an excess supply of labor, employers can choose the most profit maximizing wages out of all possible $\hat{w}(\tilde{e})$. The employers' problem is then to choose $\tilde{e}$ to maximize

$$
\max _{\tilde{e}} \pi(\tilde{e})=10(p \tilde{e}+(1-p) 1)-w(\tilde{e})
$$

Taking a derivative over $\tilde{e}$ and setting it to 0 after substituting the definition of $w(\tilde{e})$, we arrive at:

$$
\frac{\partial \pi}{\partial \tilde{e}}=10 p-5-\frac{c^{\prime}(\tilde{e})}{2}=0
$$

and hence an employer's profit is maximized when $c^{\prime}(\tilde{e})=20 p-10$, which implies employer should offer $\hat{w}(\tilde{e})$ with any $\tilde{e}$ that satisfy the condition above. Solving this for the menu of effort costs, we arrive at $c^{\prime}(\tilde{e})=1$ when $p=0.55, c^{\prime}(\tilde{e})=2$ when $p=0.60$, and $c^{\prime}(\tilde{e})=3$ when $p \geq 0.65$.

\section{Proposition 2}

Proof First consider the number of employers that will make offers to non-incumbent workers. First $t_{t} F$ employers will make such offers since they have not yet contracted with any workers. In addition, the Return ${ }_{t} F$ employers will be reentering the market at period $t$. The probability that their workers has switched employers in their absence is $r_{t-1}$, resulting in Return $r_{t-1} F$ unmatched employers.

Now consider the number of workers that will be targeted for these offers. Employers will avoid the Renew ${ }_{t} F$ workers that have incumbent employers from period $t-1$ since these pairs will reconnect unless these workers have shirked. $\operatorname{Return}_{t}\left(1-r_{t-1}\right) F$ other workers will receive reconnection offers from returning incumbent employers. This leaves $W-\left(\operatorname{Renew}_{t}-\operatorname{Return}_{t}\left(1-r_{t-1}\right)\right) F$ workers available for contracting. 
The chance that any available worker will receive an offer is therefore the number of offers divided by the number of available workers. Substituting First $_{t}=\delta^{t-1}(1-\delta)$, Renew $w_{t}=(1-\delta)^{2}$, and Renew ${ }_{t}=(1-\delta)\left(\delta-\delta^{t-1}\right)$ and simplifying, we arrive at

$$
r_{t}=\frac{(1-\delta)\left(\delta^{t-1}+\left(\delta-\delta^{t-1}\right) r_{t-1}\right) F}{W-(1-\delta)\left(1-\delta+\left(\delta-\delta^{t-1}\right)\left(1-r_{t-1}\right)\right) F}
$$

\section{Proposition 3}

\section{Proof}

- Step 0 Period $t=T$. The market proceed as in the one period market in Proposition 1.

- Step 1 (Behavior of fair workers at $t<T$ )

Fair workers will provide the requested effort regardless of whether the hiring employer is an incumbent employer or a new employer since in equilibrium all employers will only offer fair wages.

- Step 2 (Behavior of selfish workers at $t=T-1$ )

At period $T-1$ selfish workers who receive an offer of $\hat{w}\left(e_{T-1}^{\tilde{T}}\right)$ decides whether or not to shirk. A worker that does not shirk will need to bear the cost of effort this period, earning $\hat{w}\left(e_{T-1}\right)-c\left(e_{T-1}^{\tilde{T}}\right)$ and will find himself in one of three situation at the last period:

- With probability $1-\delta$, he will be offered $\hat{w}\left(\tilde{e}_{T}\right)$ at the last period $(T)$ by his incumbent employer.

- With probability $\delta r_{T}$, his employer will be out of the labor market but he will receive an offer of $\hat{w}\left(\tilde{e}_{T}\right)$ from a new employer. (Proposition 2)

- With probability $\delta\left(1-r_{T}\right)$, his employer will be out of the labor market and he does not receive an offer from a new employer and earn the unemployment pay of 5 .

Therefore the expected future payoff for workers for not shirking in period $T-1$ is:

$$
V_{T-1}=(1-\delta) \hat{w}\left(\tilde{e_{T}}\right)+\delta\left(r_{T} \hat{w}\left(\tilde{e_{T}}\right)+\left(1-r_{T}\right) 5\right)
$$

A worker that shirk at $T-1$ does not put in any costly effort and gains the full $\hat{w}\left(e_{T-1}^{\tilde{T}}\right)$. At period $T$ he will find himself in one of the following situations:

- With probability $\delta$, his firm cannot hire due to an interruption, hence covering up his shirking. With probability $r_{T}$ another firm will offer him $\hat{w}\left(\tilde{e}_{T}\right)$ and with probability $1-r_{T}$ he earn only the unemployment pay of 5 . 
- With probability $1-\delta$, his incumbent employer will be in the labor market but hiring someone else, exposing his shirking. He will earn only the unemployment pay of 5 .

Therefore the expected future payoff for workers for not shirking in period $T-1$ is:

$$
V_{T-1}^{\prime}=(1-\delta) 5+\delta\left(r_{T} \hat{w}\left(\tilde{e_{T}}\right)+\left(1-r_{T}\right) 5\right)
$$

Plugging $V_{T-1}$ and $V_{T-1}^{\prime}$ into $c\left(\tilde{e_{t}}\right) \leq V_{t}-V_{t}^{\prime}$ and simplifying, we find that to get nonminimal effort from selfish workers at period $T-1$, an offer has to satisfy:

$$
c\left(\tilde{e_{T-1}}\right) \leq(1-\delta)\left(\hat{w}\left(\tilde{e_{T}}\right)-5\right)
$$

For $p=0.55$, working backwards from $\tilde{e_{T}}=2$, an effort level of $\tilde{e_{T-1}}=4$ is sustainable for $\delta=0.1$, while $\delta=0.5$ can only sustain an effort level of $\tilde{e}_{T-1}=3$.

- Step 3: (behavior of selfish workers at $t<T$ )

To compute $V_{t}$ more generally, let's first define for the selfish type the future payoff of getting an offer at period $t, u_{t}$, and the corresponding payoff for not getting an offer $u_{t}^{\prime}$ :

$$
\begin{aligned}
& u_{t}= \begin{cases}\hat{w}\left(\tilde{e_{T}}\right) & \text { if } t=T \\
\hat{w}\left(\tilde{e_{t}}\right)-c\left(\tilde{e_{t}}\right)+V_{t} & \text { otherwise }\end{cases} \\
& u_{t}^{\prime}= \begin{cases}5 & \text { if } t=T \\
5+r_{t+1} u_{t+1}+\left(1-r_{t+1}\right) u_{t+1}^{\prime} & \text { otherwise }\end{cases}
\end{aligned}
$$

A worker that does not shirk will get an offer at $t+1$ if the employer is operation. If the employer is shut down (with probability $\delta$ ), with $r_{t}$ the worker switch employers and with probability $1-r_{t}$ the worker remain unemployed but still connected to the incumbent employer.

$$
V_{t}=(1-\delta) u_{t+1}+\delta\left(r_{t+1} u_{t+1}+\left(1-r_{t+1}\right)\left(5+V_{t+1}\right)\right)
$$

Similarly, a worker that shirks will cover up his shirking if his employer is shut down the next period. If the employer is not shut down, he will get unemployment and be disconnected from this employer.

$$
V_{t}^{\prime}=\delta r_{t+1} u_{t+1}+\delta\left(1-r_{t+1}\right) u_{t+1}^{\prime}+(1-\delta) u_{t+1}^{\prime}
$$

Equilibrium offer that keeps selfish types from shirking must satisfy $c\left(\tilde{e}_{t}\right) \leq V_{t}-V_{t}^{\prime}$. If no $c\left(\tilde{e}_{t}\right)$ satisfy this condition, the employer's best choice is to treat the game as a series of one-shot games. Substituting $e_{T-1}$ from Step 2 into the equations above for $\delta=0.1$ and $\delta=0.5$, we arrive at the effort schedule table in Proposition 3. 
Supplementary information The online version contains supplementary material available at (https://doi. org/10.1007/s10683-020-09697-1).

\section{References}

Amuedo-Dorantes, C. (2000). Work transitions into and out of involuntary temporary employment in a segmented market: Evidence from Spain. ILR Review, 53, 309-325.

Anderson, S. P., Goeree, J. K., \& Holt, C. A. (2001). Minimum-effort coordination games: Stochastic potential and logit equilibrium. Games and Economic Behavior, 34, 177-199.

Andreoni, J. (1988). Why free ride? Strategies and learning in public goods experiments. Journal of Public Economics, 37, 291-304.

Andreoni, J., \& Croson, R. (2008). Partners versus strangers: Random rematching in public goods experiments. Handbook of Experimental Economics Results, 1, 776-783.

Azariadis, C. (1975). Implicit contracts and underemployment equilibria. Journal of Political Economy, 83, 1183-1202.

Banerjee, A. V., \& Duflo, E. (2000). Reputation effects and the limits of contracting: A study of the Indian software industry. The Quarterly Journal of Economics, 115, 989-1017.

Barlevy, G. (2002). The sullying effect of recessions. The Review of Economic Studies, 69, 65-96.

Bartling, B., Fehr, E., Huffman, D., \& Netzer, N. (2018). "The causal effect of trust," University of Zurich, Department of Economics, working paper.

Bernard, M., Fanning, J., \& Yuksel, S. (2018). Finding cooperators: Sorting through repeated interaction. Journal of Economic Behavior \& Organization, 147, 76-94.

Brandts, J., Cooper, D. J., \& Weber, R. A. (2014). Legitimacy, communication, and leadership in the turnaround game. Management Science, 61, 2627-2645.

Brown, M., Falk, A., \& Fehr, E. (2004). Relational contracts and the nature of market interactions. Econometrica, 72, 747-780.

Cajner, T., Crane, L. D., Decker, R. A., Grigsby, J., Hamins-Puertolas, A., Hurst, E., Kurz, C., \& Yildirmaz, A. (2020). "The US labor market during the beginning of the pandemic recession," Technical report, National Bureau of Economic Research.

Camerer, C. F. (2003). Behavioral game theory: Experiments in strategic interaction. Princeton: Princeton University Press.

Chaudhuri, A. (2018). Belief heterogeneity and the restart effect in a public goods game. Games, 9, 96.

Chevalier, J., \& Ellison, G. (1997). Risk taking by mutual funds as a response to incentives. Journal of Political Economy, 105, 1167-1200.

Croson, R. (1996). Partners and strangers revisited. Economics Letters, 53, 25-32.

Davis, S. J., \& Haltiwanger, J. (1992). Gross job creation, gross job destruction, and employment reallocation. The Quarterly Journal of Economics, 107, 819-863.

Di Tella, R., MacCulloch, R. J., \& Oswald, A. J. (2001). Preferences over inflation and unemployment: Evidence from surveys of happiness. American Economic Review, 91, 335-341.

Eisenberg, P., \& Lazarsfeld, P. F. (1938). The psychological effects of unemployment. Psychological Bulletin, 35, 358.

Fehr, E., \& Zehnder, C. (2009). "Reputation and credit market formation: How relational incentives and legal contract enforcement interact," University of Zurich, Department of Economics, working paper.

Fréchette, G. R. (2012). Session-effects in the laboratory. Experimental Economics, 15, 485-498.

Herrera, J., \& Shady, G. D. R. (2005). "Labor Market Transitions in Peru," Technical report, Ibero-America Institute for Economic Research.

Kahneman, D., \& Krueger, A. B. (2006). Developments in the measurement of subjective well-being. Journal of Economic Perspectives, 20, 3-24.

Lazear, E. P., Shaw, K. L., \& Stanton, C. (2016). Making do with less: Working harder during recessions. Journal of Labor Economics, 34, 333-360.

Linardi, S., \& McConnell, M. A. (2011). No excuses for good behavior: Volunteering and the social environment. Journal of Public Economics, 95, 445-454.

Lindbeck, A., \& Snower, D. J. (2001). Insiders versus outsiders. Journal of Economic Perspectives, 15, 165-188. 
Lucas, R. E., Clark, A. E., Georgellis, Y., \& Diener, E. (2004). Unemployment alters the set point for life satisfaction. Psychological Science, 15, 8-13.

Macchiavello, R., \& Morjaria, A. (2015). The value of relationships: Evidence from a supply shock to Kenyan rose exports. American Economic Review, 105, 2911-45.

Palfrey, T. R., \& Prisbrey, J. E. (1997). Anomalous behavior in public goods experiments: How much and why? The American Economic Review, 87, 829-846.

Paul, K. I., \& Moser, K. (2009). Unemployment impairs mental health: Meta-analyses. Journal of Vocational Behavior, 74, 264-282.

Renner, E., \& Tyran, J.-R. (2004). Price rigidity in customer markets. Journal of Economic Behavior \& Organization, 55, 575-593.

Rute Cardoso, A., \& Portela, M. (2009). Micro foundations for wage flexibility: Wage insurance at the firm level. Scandinavian Journal of Economics, 111, 29-50.

Van Huyck, J. B., Battalio, R. C., \& Beil, R. O. (1990). Tacit coordination games, strategic uncertainty, and coordination failure. The American Economic Review, 80, 234-248.

Van Huyck, J. B., Battalio, R. C., \& Beil, R. O. (1991). Strategic uncertainty, equilibrium selection, and coordination failure in average opinion games. The Quarterly Journal of Economics, 106, 885-910.

Williamson, O. E., Wachter, M. L., \& Harris, J. E. (1975). Understanding the employment relation: The analysis of idiosyncratic exchange. The Bell Journal of Economics, 6, 250-278.

Publisher's Note Springer Nature remains neutral with regard to jurisdictional claims in published maps and institutional affiliations. 